\title{
Neocucullanus neocucullanus Travassos, Artigas et Pereira, 1928 (Nematoda: Cucullanidae) from the Characidae fish, Brycon hilarii Valenciennes, 1850, from Brazil
}

\author{
Aurélia Saraiva/*/+ , Fabiana Aparecida da Silva**, Ângela Teresa Silva-Souza*** \\ Departamento de Zoologia e Antropologia, Faculdade de Ciências, Universidade do Porto, Praça Gomes Teixeira, 4099-002 \\ Porto, Portugal *Centro Interdisciplinar de Investigação Marinha e Ambiental, Porto, Portugal **Universidade do Estado \\ de Mato Grosso, Cuiabá, MT, Brasil ***Departamento de Biologia Animal e Vegetal, Centro de Ciências Biológicas, \\ Universidade Estadual de Londrina, Londrina, PR, Brasil
}

During investigation on the helminth parasites from Brycon hilarii Valenciennes, 1850 (Characiformes, Characidae), from River Juba, Tangará da Serra, state of Mato Grosso, Brazil, several specimens of the nematode Neocucullanus Travassos, Artigas et Pereira, 1928 were detected. A detailed study of this material, including scanning electron microscopy, allowed to identify these nematodes as N. neocucullanus Travassos, Artigas et Pereira, 1928 and to confirm N. multipapillatus Petter, 1989 as a junior synonym of N. neocucullanus.

Key words: characid fish - Brycon hilarii - nematode - Neocucullanus - Brazil

During investigation on the helminth parasites from the Characid fish, Brycon hilarii Valenciennes, 1850, from River Juba, Tangará da Serra, state of Mato Grosso, Brazil, several specimens of the nematode Neocucullanus Travassos, Artigas et Pereira, 1928 were collected. To date only two species of Neocucullanus have been reported both in the intestine of characid fishes (Moravec 1998). N. neocucullanus Travassos, Artigas et Pereira, 1928 was detected in the River das Velhas basin, Lassance, state of Minas Gerais, Brazil (Travassos et al. 1928) and recently in the Usumacinta River, Frontera Echeverria, state of Chiapas, Mexico (Caspeta-Mandujano et al. 2005). N. multipapillatus Petter, 1989 was detected in Paraná River basin, Arroyo, Tagatija-guazu, Conception Province, Paraguay (Petter 1989). According to Petter (1989) N. multipapillatus differs from $N$. neocucullanus mostly by the absence of small caudal alae and the presence of one unpaired precloacal papilla on the male posterior extremity. A detailed study of the material collected in the present work, including scanning electron microscopy (SEM), allowed to identify these nematodes as $N$. neосисullanus and to confirm $N$. multipapillatus as a junior synonym of N. neocuccullanus.

\section{MATERIALS AND METHODS}

Fish specimens ( $\mathrm{n}=60$ ) were captured from River Juba $\left(14^{\circ} 50^{\prime} 09.9^{\prime \prime} \mathrm{S}\right.$ and $\left.57^{\circ} 51^{\prime} 13.5^{\prime \prime} \mathrm{W}\right)$, Tangará da Serra, state of Mato Grosso, Brazil, from August 2003 to January 2004, by fishing rods. Fishes were deep-frozen after capture and dissected in the laboratory. Nematodes recovered from digestive tract were washed in physiological saline, fixed in 5\% formalin and stored in $70 \%$ ethanol. For light

${ }^{+}$Corresponding author: amsaraiv@fc.up.pt

Received 28 April 2006

Accepted 5 July 2006 microscope examination, nematodes were cleared in glycerine. Drawings were made with the aid of a Zeiss microscope drawing attachment using Nomarski's interference contrast. Two specimens (one male and one female) were dehydrated through a graded ethanol series, critical point dried, coated with gold and examined in a SEM.

RESULTS

Neocucullanus neocucullanus

(Figs 1-2)

Description - Large sized nematodes without lateral alae. Oral opening elongated dorsoventrally surrounded by membranous collarette with row of numerous denticles. Four submedian cephalic papillae. Oesophagus muscular more or less equally expanded at its anterior and posterior parts. Pseudobuccal capsule (oesophastome) well developed. Oesophagus lumen sclerotized up to posterior part of nerve ring. Nerve ring prominent in the posterior part of first half of oesophagus. Deirids well visible and well posterior to nerve ring. Excretory pore in region of deirids. Intestinal caecum absent. Pair of small lateral phasmids present in tail. Tail rounded with terminal mucron.

Male (based on 3 specimens) - Length of body 16-24 mm, width $0.49-0.81 \mathrm{~mm}$. Entire oesophagus $0.92-1.15 \mathrm{~mm}$ long, minimum width $0.08-0.13 \mathrm{~mm}$, maximum width $0.19-0.22 \mathrm{~mm}$. Oesophastome $0.20-0.21 \mathrm{~mm}$ long and $0.09-0.11 \mathrm{~mm}$ wide. Nerve ring, excretory pore (observed in one specimen) and deirids $0.41-0.47 \mathrm{~mm}, 0.71 \mathrm{~mm}$, and $0.65-0.82 \mathrm{~mm}$, respectively, from anterior extremity. Precloacal sucker present, situated $1.00-1.30 \mathrm{~mm}$ from posterior extremity. 14 pairs of caudal papillae: 10 preanal ( 3 pairs subventral and anterior to sucker; 3 pairs subventral at level of sucker; 2 pairs subventral posterior to sucker; and 2 pairs subventral between unpair median preanal papilla and anal aperture) and 4 postanal (3 subventral and 1 lateral). Unpair median preanal papilla proeminent. Spicules broad 0.49$0.73 \mathrm{~mm}$ long, with rounded and moderately scerotized distal ends. Gubernaculum absent. Tail rounded 0.19-0.32 $\mathrm{mm}$ long with terminal mucron. 
Female (based on 6 specimens) - Length of body 21-48 $\mathrm{mm}$, maximum width $0.65-0.90 \mathrm{~mm}$. Entire oesophagus 1.05 $1.25 \mathrm{~mm}$, minimum width $0.08-0.11 \mathrm{~mm}$, maximum width 0.20 $0.25 \mathrm{~mm}$. Oesophastome $0.21-0.24 \mathrm{~mm}$ long and $0.11-0.15$ $\mathrm{mm}$ wide. Nerve ring, excretory pore (observed in one specimen) and deirids 0.43-0.47 mm, $0.85 \mathrm{~mm}$ and 0.79-0.94 $\mathrm{mm}$, respectively, from anterior extremity. Vulva pos-equatorial $10-18 \mathrm{~mm}$ from posterior extremity. Vulval lips elevated. Tail 0.20-0.26 mm long with terminal mucron.

\section{Host - Brycon hilarii.}

Site of infection - Intestine and pyloric caecum.

Locality - River Juba, state of Mato Grosso, Brazil (14 $50^{\circ}$ 09.9"S, 57 51'13.5”'W).
Prevalence and intensity $-13.3 \%$ and $1.6 \pm 0.52(1-2)$.

Deposition of voucher specimens - Instituto Oswaldo Cruz, Rio de Janeiro, Brazil (35446, 35447).

In the present study specimens of $N$. neocucullanus were only detected in the wet season.

\section{DISCUSSION}

The genus Neocucullanus Travassos, Artigas et Pereira, 1928 is easily distinguished from other genera of Cucullanidae which occur in fish by a short and rounded caudal extremity and by very broad spicules with rounded distal extremity (Petter 1989, Moravec 1998).

The specimens studied in this work were initially iden-
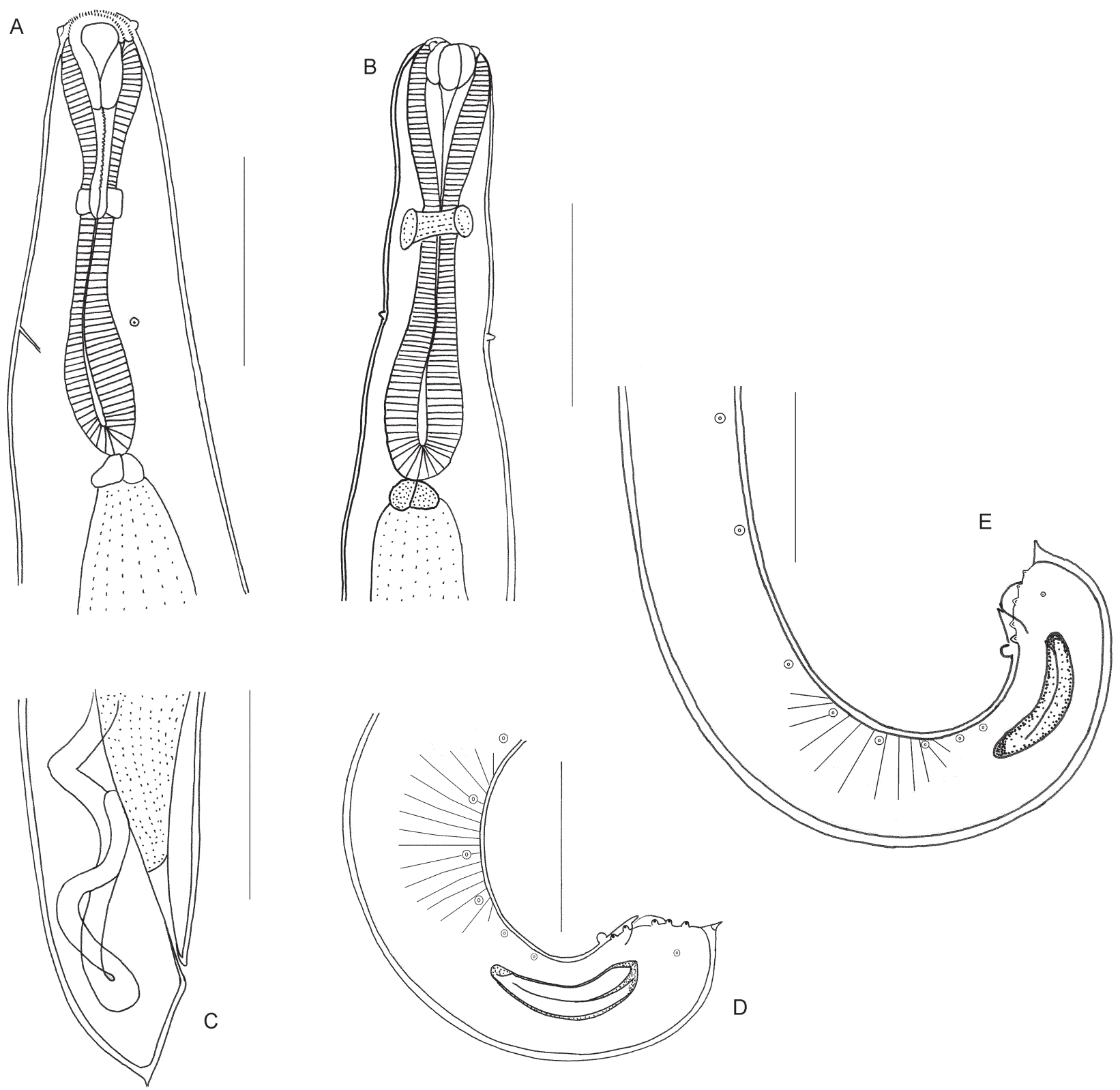

Fig. 1: Neocucullanus neocucullanus. A, B: anterior end of body, lateral and dorsoventral views; C: posterior end of female, lateral view; D, E: posterior end of male, lateral views. Scale bar: A, B, C, and $E=0.5 \mathrm{~mm}, \mathrm{D}=1 \mathrm{~mm}$. 

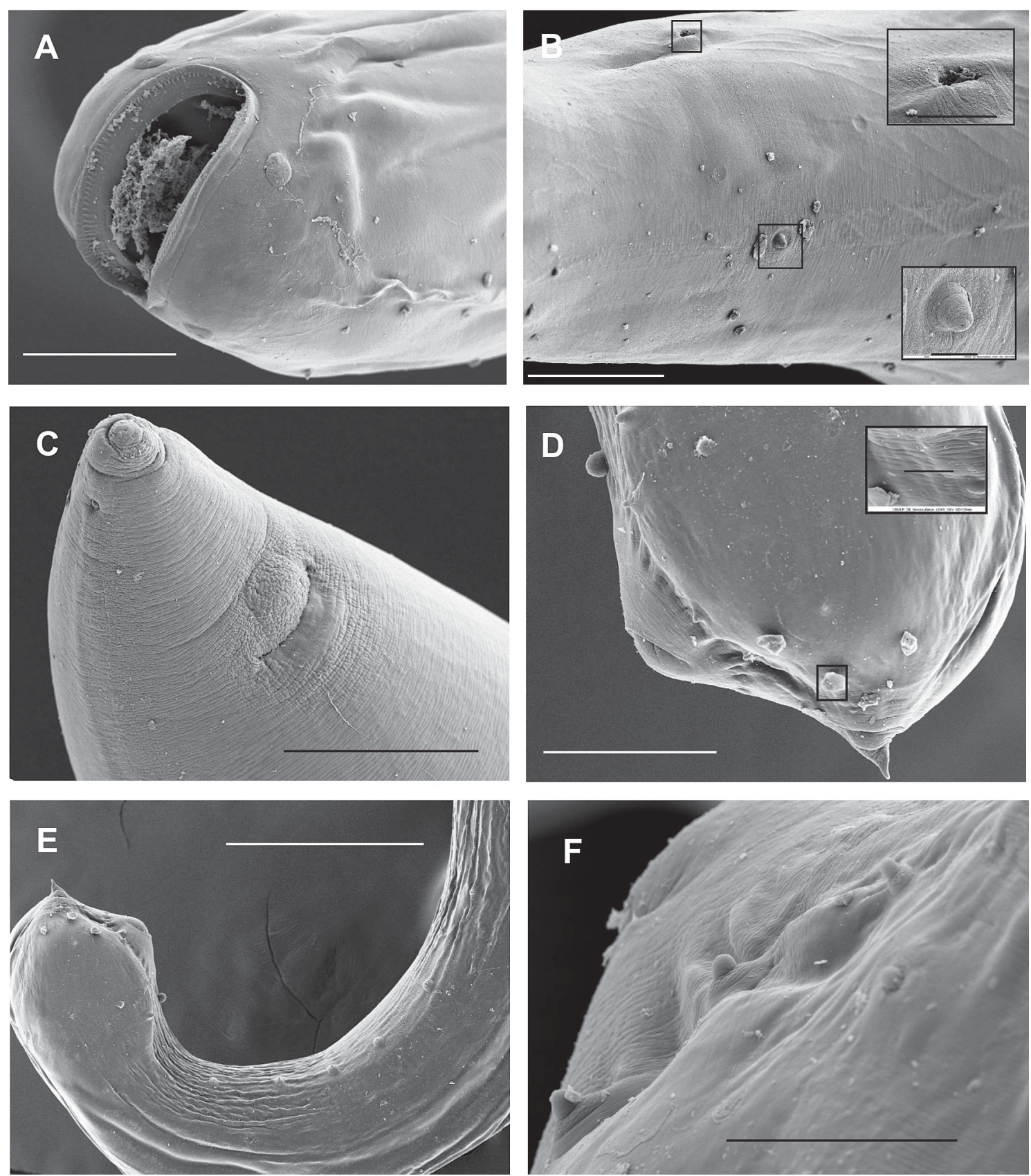

Fig. 2: Neocucullanus neocucullanus, scanning electron micrographs. A: cephalic end; B: position of excretory pore and deirid, ventrolateral view. Inserted excretory pore (scale bar $=20 \mu \mathrm{m}$ ) and deirid (scale bar $=10 \mu \mathrm{m})$; C: tail of female; D: tail of male, lateral view. Inserted postanal lateral papilla partially occluded (scale bar $=16 \mu \mathrm{m}$ ); E: posterior extremity of male, lateral view; F: tail of male with well visible postanal papillae (3 subventral and 1 lateral). Scale bar: A, B, C and D $=100 \mu \mathrm{m}, \mathrm{E}=300 \mu \mathrm{m}, \mathrm{F}=30 \mu \mathrm{m}$.

tified as $N$. multipapillatus because, as it is defined for this species, they have not caudal alae and present an unpaired precloacal papilla. The position of deirids, posterior to nerve ring level, was also in accordance to this species description, and differed from N. neocucullanus described by Travassos et al. (1928) since the drawings of these authors showed the deirids at nerve ring level. On the other hand the absence of gubernaculum as well as the number of preanal papillae (10) observed is in ac- cordance to N. neocucullanus description. Petter (1989) observed 9 pairs of preanal and 5 pairs of postanal papillae in N. multipapillatus.

Caspeta-Mandujano et al. (2005) detected specimens considered as N. neocucullanus in B. guatemalensis from Mexico. Althought they were very similar to those found in the present study, these authors referred the presence of 13 pairs of caudal papillae in males; 8 preanal (plus the unpaired median papilla), 1 adanal and 4 postanal ( 3 
subventral and 1 lateral). During this study we noticed that according to Reis et al. (2003) and Froese and Pauly (2005) B. microlepis Perugia, 1897, the fish host where Petter detected $C$. multipapillatus, was considered a junior synonym of $B$. hilarii. On the other hand Travassos et al. (1928) detected N. neocucullanus in a "Characidae sp." and it is possible that this species belongs to the genera Brycon. According to Petter (1989) the two species are very similar and in her opinion it can not be excluded, after the study of more specimens, that both species could be considered the same.

All these observations confirm $N$. multipapillatus as a junior synonym of $N$. neocucullanus which is a Neotropical nematode that can occur in several species of the genus Brycon Müller \& Troschel, 1844 and has been detected so far in Mexico, Brazil, and Paraguay.

\section{REFERENCES}

Caspeta-Mandujano JM, Cabanas-Carranza G, Salgado-
Maldonado G, Gosztonyi AE, Cremonte F 2005. Nematode parasites of the characid freshwater fish Brycon guatemalensis in the Usumacinta River, Chiapas, Mexico. Helminthologia 42: 41-44.

Froese R, Pauly D 2005. Fish Base World Wide Web Electronic Publication, www.fishbase.org, version (11/2005).

Moravec F 1998. Nematodes of Freshwater Fishes of the Neotropical Region, Academia, Prague, 464 pp.

Petter AJ 1989. Nematode parasites of Paraguayan Fishes. 5. Description of two new species of Cucullanidae and redefinition of the genus Neocucullanus Travessos et al. Rev Suisse Zool 96: 591-603.

Reis RE, Kullander SO, Ferraris Jr CJ 2003. Check List of the Freshwater Fishes of South and Central America, EDIPUCRS, Porto Alegre, 742 pp.

Travassos L, Artigas P, Pereira C 1928. Fauna helminthologica dos peixes de água doce do Brasil. Arch Inst Biol São Paulo 1: 5-68. 